\title{
Ambiguous Adaptation The Effect of Contract Duration and Investments in Relational Mechanisms on Premature Relationship Termination
}

Møller Larsen, Marcus; Lyngsie, Jacob

Document Version

Accepted author manuscript

Published in:

Long Range Planning

DOI:

10.1016/j.Irp.2016.11.006

Publication date:

2017

License

CC BY-NC-ND

Citation for published version (APA):

Møller Larsen, M., \& Lyngsie, J. (2017). Ambiguous Adaptation: The Effect of Contract Duration and Investments in Relational Mechanisms on Premature Relationship Termination. Long Range Planning, 50(6), 794-808. https://doi.org/10.1016/j.lrp.2016.11.006

Link to publication in CBS Research Portal

\section{General rights}

Copyright and moral rights for the publications made accessible in the public portal are retained by the authors and/or other copyright owners and it is a condition of accessing publications that users recognise and abide by the legal requirements associated with these rights.

\section{Take down policy}

If you believe that this document breaches copyright please contact us (research.lib@cbs.dk) providing details, and we will remove access to the work immediately and investigate your claim. 


\section{Ambiguous Adaptation: The Effect of Contract Duration and Investments in Relational Mechanisms on Premature Relationship Termination} Marcus Meller Larsen and Jacob Lyngsie Journal article (Accepted manuscript)

CITE: Møller Larsen, M., \& Lyngsie, J. (2017). Ambiguous Adaptation: The Effect of Contract Duration and Investments in Relational Mechanisms on Premature Relationship Termination. Long Range Planning, 5ab), 794-808. 001: 10.1016/j.Irp.2016.11.006 DOI: 10.1016/j.Irp.2016.11.006 


\title{
AMBIGUOUS ADAPTATION: THE EFFECT OF CONTRACT DURATION AND INVESTMENTS IN RELATIONAL MECHANISMS ON PREMATURE RELATIONSHIP TERMINATION
}

\author{
Marcus M. Larsen* \\ Department of Strategic Management and Globalization \\ Copenhagen Business School \\ Kilevej 14, 2. floor - 2000 Frederiksberg - Denmark \\ mml.smg@cbs.dk / (+45) 38155628 \\ Jacob Lyngsie \\ Department of Strategic Management and Globalization \\ Copenhagen Business School \\ Kilevej 14, 2. floor - 2000 Frederiksberg - Denmark \\ jl.smg@cbs.dk / (+45) 38155625
}

\begin{abstract}
We investigate the connection between contract duration, relational mechanisms, and premature relationship termination. Based on an analysis of a large sample of exchange relationships in the global service-provider industry, we argue that investments in either longer contract duration or more intense relational mechanisms provide an effective means for contingency adaptation and therefore reduce the probability of premature termination. However, in situations where relationships are already governed by longer duration contracts, we argue that investments in relational mechanism create ambiguous reference points for adaption and thus increase the likelihood of premature termination by restricting the parties' set of adaptive actions.
\end{abstract}

Keywords: Premature relationship termination, contract duration, informal governance, adaptation, service-provider industry. 


\section{INTRODUCTION}

Firms routinely enter exchange relationships with the purpose of trading goods or services for a predetermined period (Parmigiani and Rivera-Santos, 2009). However, it is also common for firms in exchange relationships to encounter substantial and unanticipated contingencies (e.g., Larsen, Manning, and Pedersen, 2013). Contingencies may change the appropriation structure of an exchange relationship and enable opportunistic behavior. Disturbances may alter the profit structure of the exchange and consequently undermine the longevity of the relationship. Thus, to fulfill contractual commitments given unforeseen disturbances, the exchange relationship has to be able to adapt to the changing circumstances (Williamson, 1975). Unless successful adaptation occurs, firms may be left with no other option but to terminate the relationship before the predetermined contract expiration (e.g., Weber, Mayer, and Macher, 2011).

In this article, we seek to understand how investments in relational mechanisms to relationships already governed by long-term contracts affects the probability of premature termination. Accordingly, we investigate the relationship between predetermined and effective relationship duration given investments in relational mechanisms. We emphasize that contract duration is a key mechanism for effectively governing exchange relationships (cf., Joskow, 1987; 1988). In fact, analyses of transaction-cost economics start from the assertion that formal governance forms such as contract duration are carefully chosen to match the properties of the focal exchange. Exchange relationships are governed by the structure that economizes on transaction costs (Coase, 1937; Williamson, 1975) and effectively guards against opportunistic rent appropriation (Klein, Crawford and Alchian, 1978). Increased predetermined contract duration enables exchange partners to more easily avert or safeguard against exchange hazards, especially when asset specific investments are necessary (Ciccotello et al., 2005; Joskow, 1988). 
Moreover, longer duration contracts allow for flexible adaptive action that reduces the likelihood of shorter than expected duration. At the same time, however, research has also documented how firms rely on informal governance mechanisms, such as trust, common norms, and reciprocity between transacting parties to ensure ex-post mutual and flexible adaption to contingencies (Poppo et al., 2008; Puranam and Vannestre, 2009; Zaheer and Venkatraman, 1995). In this regard, we focus specifically on investments in relational mechanisms to nurture the longevity of the relationship, wherein adaptation emerges as a result of reciprocal trust building and the shared values and processes build on the parties' social relationship (Poppo and Zenger, 2002). Thus, by relying on relational mechanisms, exchange partners are afforded with adaptive structures necessary to reduce the risk of premature relationship termination.

We hypothesize that both contract duration and investments in relational mechanisms provide firms with structures enabling adaption to unanticipated disturbances that may jeopardize the value of an exchange relationship (Argyres and Mayer, 2007; Poppo and Zenger, 2002; Williamson, 2002). However, in situations where firms invest in relational mechanisms to exchange relations already governed by long-term contracts, we argue that parties will be less likely to successfully adapt to contingencies, which makes premature termination more probable. Specifically, we propose that while effective governance structures individually create a common and unanimous point of reference that guides adaptive behavior (Hart and Moore, 2006; Hart, 2008; Fehr et al., 2014), the simultaneous existence of different governance mechanisms creates multiple reference points for adaptive action. This, we argue, induces a higher risk of ambiguity and non-converging preferences for adaptive behavior. Parties are less likely to share views of how to adapt (Hart and Moore, 2006), and are more likely to develop diverging feelings of entitlement (Pinkley and Northcraft, 1994). Thus, we propose that investments in relational mechanisms in 
relationships already governed by long-term contracts increases the likelihood of premature termination. We test these arguments using a large sample of exchange relationships between clients and international service providers. Our results indicate that the reliance on either longterm contracts or relational mechanisms reduces the probability of premature relationship termination. On the other hand, augmenting long-term contracts with relational mechanisms increases the likelihood of premature termination.

Our study contains several contributions to the extant literature on exchange governance. We focus on premature relationship termination, a topic that - to the best of our knowledge - has received little systematic scrutiny in strategic management research (see Schepker et al., 2014). Our focus is motivated by the potentially substantial value loss associated with prematurely terminated exchange relationships. Although firms may seek to contractually regulate premature termination (e.g., Goldberg, 1976), bilateral dependence and relation-specific investments between transacting parties make premature termination particularly costly (Williamson, 2002). Hence, it is imperative to enhance our understanding of the connection between different governance mechanisms and contingency adaptation. In this respect, we extend recent examinations of the relationship between formal and informal governance structures by focusing on the ability of parties to adapt to contingencies (e.g., Poppo and Zenger, 2002; Puranam and Vanneste, 2009; Schepker et al., 2014). We do so by arguing that governance structures essentially function as reference points for adaptation (Hart and Moore, 2006), and that ambiguity in the choice of adaptive action reduces the likelihood that the transacting parties will adjust to disturbances.

\section{THEORY AND HYPOTHESES}

Premature relationship termination 
Interorganizational exchange can take multiple forms and can vary in terms of recurrence, temporal duration, and governance structure (e.g., Ring and Van de Ven, 1992; Parmigiani and Rivera-Santos, 2009). In this article, we focus on premature relationship termination, defined as the effective termination of an exchange relationship before the predetermined expiration date. Premature termination therefore signifies cases where expected contract duration exceeds effective contract duration. Our analysis therefore excludes exchanges in which firms engage in ongoing relationships (i.e., without a predetermined relationship duration), such as strategic alliances.

Premature termination is a common phenomenon in fixed-duration relationships (Weber et al., 2011). For example, in 2004, the LEGO Group_one of the world's largest manufacturers of toys - signed a long-term contract with Flextronics, a large Singaporean electronics manufacturing services provider, to outsource up to $80 \%$ of its production (Larsen et al., 2010). This decision reflected a desire to cut costs by procuring production from plants in low-cost locations while exploiting economies of scale by having one party handle the majority of production. However, as a result of problems such as disagreements over how to respond to substantial seasonal fluctuations in demand for LEGO products, the outsourcing contract was terminated prematurely after only a few years. As a result, LEGO was forced to undertake the extensive process of reintegrating the widespread network of production facilities.

The consequences of premature termination are far from trivial. For example, bilateral dependence and relation-specific investments between transacting parties make premature termination particularly costly (Williamson, 2002). The buyer in the relationship may find it difficult and costly to identify a replacement for a supplied good due to specific investments or time-compression diseconomies. Conversely, suppliers that have made relation-specific 
investments may incur losses if they have to deploy assets in a second-best alternative use (Klein et al., 1978).

An important reason for the premature termination of exchange relationships relates to nonconformity with the contractual obligations of the exchange. ${ }^{1}$ Non-conformity with contractually established obligations is often assumed to cause termination. For example, in a study of the broiler industry where chickens are raised for meat, Knoeber (1989) finds that contracts are terminated prematurely if the grower's performance consistently fails to meet the requirements stipulated in the formal contract (see also Ganglmair, 2009).

More generally, it can be argued that premature relationship termination results from the inability of transacting parties to exercise adaptive behavior when faced with unanticipated contingencies during the predetermined period of the contractual engagement. According to Williamson (1996: 229), adapting to contingencies remains "the central problem of economic exchange." Unanticipated contingencies that change the circumstances of the transaction in ways not explicitly covered by the contract can create bargaining opportunities and opportunistic behavior, which together challenge the continuity of the relationship. Argyres and Mayer (2007: 1069) argue that "too little time spent on important contingencies can result in conflict during the execution of the project, which can, in turn, cause premature termination of the project and/or the relationship." Thus, when unanticipated circumstances jeopardize the value of the exchange relationship, effective adaption ensures that the parties are incentivized to deliver on the promise of the exchange (Williamson, 1996; 2002).

\footnotetext{
${ }^{1}$ Exchange relationships may also be prematurely terminated in cases where parties' efficiency is higher than originally expected, such that the exchange of resources is completed ahead of the predetermined termination date. However, we assume that such cases rarely occur as an antecedent of premature termination and that other factors such as contractual breaches are more common. Regardless, situations of over-compliance are not materially different, as they comprise a special case of contingency adaptation.
} 


\section{*** Figure 1 about here ***}

Extant research has focused on a number of formal and informal mechanisms of adaptive behavior (see Figure 1), such as managerial fiat, abandonment/renegotiation (Williamson, 1985), and contractual provisions (Klein et al 1978; Weber et al., 2011) as well as reciprocal trust building (Macneil, 1978), open communication (Kale et al., 2002), and information exchange (Dyer and Singh, 1998). In the following we build specific hypotheses regarding the influence of expected relationship duration (i.e., predetermined contractual duration) and investments in relationship nurturing mechanisms on premature termination.

\section{Adaptation and contract duration}

In terms of understanding the connection between predetermined contract duration-defined as "the length of time to which the parties agree ex ante to abide by the terms of a contract" (Jaskow, 1987: 169) — and premature termination, we emphasize the adaptive role of formal governance structures. Following transaction cost economics (Williamson, 1985), variation of formal governance structures result from deliberate choices driven by the properties of the focal transaction (e.g., the level of asset specificity, uncertainty involved in the exchange, and the frequency of transaction). Although a substantial amount of research has focused on asset specificity (Shelanski and Klein, 1995), uncertainty and frequency are equally important in determining the most effective governance structure. Formal governance mechanisms have largely been examined in terms of mergers and acquisitions (i.e., the make-or-buy decision), arguably as a result of the long history of empirical research involving asset specificity and the animated debate surrounding Klein, Crawford, and Alchain's (1978) use of the GM/Fisher Body case (e.g., Coase, 2006). However, formal governance encompasses more than pure market transactions and full upstream/downstream integration. The gap between these polar forms of governance is filled by 
hybrid forms of governance, defined as "various forms of long-term contracting, reciprocal trading, regulation, franchising, and the like" (Williamson, 1991: 280).

In terms of governing exchange relationships, the emphasis under formal governance structures is often put on the conscious selection of exchange parties as well as contractual stipulations regarding joint planning, coordination of inputs, duration, quality, and standards (Shelanski and Klein, 1995). Importantly, formal governance-expected contract duration included - are characterized by ex-ante determined mechanisms for adaptation if unexpected contingencies should arise (Williamson, 1991). As asset specificity increases, transacting parties may decide to increase the duration of the contract in order to avert repeated bargaining and safeguard against exchange hazards, and thus allow for flexible adaptive action (Ciccotello et al., 2005; Joskow, 1988). As Joskow (1987: 169) argues, “A long-term contract that specifies the terms and conditions for some set of future transactions ex ante, provides a vehicle for guarding against ex post performance problems". Therefore, upon entering an exchange relationship, the transacting parties agree on a fixed-duration formal contract that details a set of obligations and rights, which aim, in part, to guide actions in case of non-compliance.

Clearly, adaption mechanisms vary among the formal modes of governance (Williamson, 1985). While adaptation in hierarchical and market-based governance modes is facilitated by managerial fiat and abandonment/renegotiation, respectively, contractual provisions provide critical mechanisms for adaptation under hybrid governance structures. In fact, in GM/Fisher Body example, the contractual form was constructed as a cost-plus contract to accommodate future changes in productions costs (Klein et al., 1978). Such 'non-standard contracting' stipulates the specific adaptive actions to undertake in the event of contingencies (Williamson, 1975; 1985). However, contracts do not necessarily provide detailed and systematic procedures for the entire 
set of possible future circumstances. Bounded rationality and opportunism among transacting parties inherently result in contracts being incomplete, either purposely or as a result of oversight (Williamson, 1985). Thus, contracts cannot fully address all potential future circumstances exante. Yet, by increasing the expected duration of the contractual agreement, exchange parties may facilitate valuable relationship specific investments and include contractual clauses that mitigate exchange hazards by specifying future adaptive actions (Joskow, 1987). Accordingly, we expect parties to more readily adapt to contingencies when increasing the duration of the contractual agreement, which reduces the likelihood of premature termination (i.e., a greater match between effective and expected duration). We formulate the following hypothesis:

Hypothesis 1: Longer expected contract duration reduces the likelihood that an exchange relationship will prematurely terminate.

\section{Adaptation and investments into relational mechanisms}

Relational mechanisms - characterized as mechanisms in "interfirm exchange which includes significant relationship- specific assets, combined with a high level of interorganizational trust" (Zaheer and Venkatraman, 1995: 374) or governance that "emerges from the values and agreedupon processes found in social relationships" (Poppo and Zenger, 2002: 709; see also Dyer and Singh, 1998) — has been highlighted as an explanatory factor for firms' abilities to create competitive advantage (Amit and Zott, 2001; Dyer and Singh, 1998; Inkpen and Tsang, 2005). Specifically, focusing on how relational norms and trust may serve as substitutes for formal contracting, the relational perspective has been viewed as an antecedent of value-creating strategic relationships. Indeed, resource complementarity, knowledge sharing, and knowledge absorption have been focal elements in explanations of superior and suboptimal performance in exchange relationships (Ethiraj et al., 2005, Lane et al., 2006). The focus on non-opportunistic cooperation 
is a critical element in the extant literature, which purports that relation-based governance mechanisms offer inherent advantages relative to formal contracting (Poppo et al., 2008).

Relational mechanisms typically based on trust, common norms and reciprocity are emphasized as crucial to ensure cooperation and collaboration (Poppo et al., 2008; Zaheer and Venkatraman, 1995). Mechanisms such as trust building (Puranam and Vannestre, 2009), noncontractual collaboration (Zaheer and Venkatraman, 1995), open communication (Kale et al., 2002) enable mutual and flexible adjustments to contingencies, focusing on collaborative enhancement of the joint surplus of the exchange (Poppo and Zenger, 2002). Positive expectations of parties' intentions and actions reduce uncertainty about adapting to potential contingencies. Essentially, investments in relational mechanisms enables exchange parties to implement changes without worrying about attempts to opportunistic redistribute value (Puranam and Vannestre, 2009).

In terms of adapting to unanticipated circumstances and, thus, reducing the likelihood of premature termination, specific adaptive behavior in contexts where partners have invested in significant relational mechanisms is not stipulated at the outset of an exchange relationship. Instead, adaptation norms evolve through continuous ex-post reciprocity that builds on values and processes that emerge through the parties' social relationship (Macneil, 1978, 1980; Heide and John, 1992). Interactions and information exchange between the parties enables contingencies to be addressed through open communication and bilateral adaptation (Kale et al., 2002). Informal structures support flexible adaptation by promoting solidarity, trust, and information exchange (Dyer and Singh, 1998). Of course, in contrast to the legal enforceability afforded formal governance mechanisms (i.e., contracts), relational governance requires continuous acceptance of the mechanisms introduced by the parties. Specifically, given the unenforceability of relational 
mechanisms, parties have to continuously nurture the relationship to ensure cooperation. Adaptation is therefore accomplished through "a bilateral approach to problem solving, creating a commitment to joint action through mutual adjustment" (Poppo and Zenger, 2002: 710). Thus, we expect that continuous nurturing of relational mechanisms provides exchange parties with consistent instruments for contingency adaptation, and thus reduce the likelihood of premature termination. This leads to the following hypothesis:

Hypothesis 2: Investments in relational mechanisms reduce the likelihood that an exchange relationship will prematurely terminate.

\section{Adaptation with multiple reference frames}

So far, we have followed established literature in suggesting how expected relationship duration and investments into relational mechanisms influence adaptive behavior that reduces the likelihood of premature termination. The main purpose of this article, however, is to understand the connection between investing in relational mechanisms in relationships with ex ante established long-term contracts. In this respect, a substantial amount of research has investigated the complementary and substitutive nature of formal and informal governance mechanisms (e.g., Poppo and Zenger, 2002; Puranam and Vanneste, 2009; Schepker et al., 2014). Some of this research has highlighted that the different mechanisms are substitutive in terms of governing transactions. For example, while complex contracts may undermine efforts to build trust (Ghoshal and Moran, 1996), informal mechanisms can undermine the role of contracts in governing transactions (Gulati and Nickerson, 2008). At the same time, research also emphasizes the potential complementarity between formal and informal governance mechanisms. For example, it has been argued that complex contracts may actually facilitate and guide trust building (Poppo and 
Zenger, 2002), while a trust-based relationship may fill gaps in formal governance structures (Arrow, 1974).

In this study, we propose a different mechanism induced by adaption requirements. Specifically, while prior research has largely focused on how different governance forms influence exchange performance (Gulati and Nickerson, 2008; Poppo and Zenger, 2002), we emphasize the behavioral consequences of adaptation. We suggest that contingencies force decision makers to create points of reference to screen and filter the environmental changes, and eventually take adaptive action (March and Simon, 1958; Hart and Moore, 2006; Kaplan, 2008; Cornelissen and Werner, 2014). Similar to the notion of conflict frames-i.e., "the lenses through disputant view a conflict situation" (Pinkley and Northcraft, 1994: 193)—we argue that exchange parties faced with unanticipated changing circumstances establish contingency frames of how to effectively adapt. These reference frames subsequently affect the likelihood of adaption and, thus, the risk of premature relationship termination.

According to this logic, a contract can be seen as providing an ex-ante mutually agreed upon common reference frame for adaption behavior. Hart and Moore (2006: 32) emphasize the behavioral role of contracts as reference points and argue that "a contract written early on when an external measure of the parties' contribution to the relationship was provided by competitive markets can continue to govern the parties' feelings of entitlement later when they become locked in to each other." Thus, exchange parties refer to the contractual foundation of the relationship to determine the consequences of a contingency and adapt their performance accordingly (see also Hart, 2008, and Fehr et al., 2014, for recent experimental evidence). Thus, formal contractual structures can be viewed as central reference points for the transacting parties' feelings of entitlement and, thus, their adaptive commitment. Although increased expected exchange duration 
increases the set of possible contingencies excluded from contracting, longer duration contracts also encompass more specified contingencies. Thus, longer duration contracts provides exchange parties with more stipulated adaptive actions to use as reference points, even under unspecified circumstances. In situations that may endanger the survival of the exchange relationship, parties will refer to the contract for specified adaptation mechanisms to guide their adaptive actions. Thus, as the predetermined contract duration increases, the common reference frame is increasingly able to directly or analogously steer adaptive behavior in situations of unanticipated disturbances. A more extensive reference frame thus increases the likelihood of converging adaptation to contingencies.

Similarly, relational mechanisms create a common contingency frame of reference for transacting parties. For example, in an exchange relationship that has scarcely invested in relational mechanisms, failure to meet a contractual obligation is likely to lead to premature termination. In contrast, a relationship characterized by strong relational mechanisms, contractual noncompliance is framed reciprocally, which may preclude premature termination. In the latter case, parties develop a convergent point of reference through the informal mechanisms. Relational mechanisms become a social contract, which functions as an effective reference point (e.g., Ostrom et al., 1992). This argument is analogous to the one forwarded by Zaheer et al. (1998: 144), who argue that "when interorganizational trust is high, negotiating positions are based on similar underlying assumptions, and agreements are likely to be reached more quickly." Therefore, in the face of contingencies, exchange parties can utilize the established trust, common norms, and reciprocity as a point of reference for adaptation.

Thus, both longer contractual duration and investments in relational mechanisms are by themselves likely to create an effective frame of reference for contingency adaptation (and, as 
such, confirm our two preceding hypotheses). However, to understand the effect of combining relational mechanisms with ex ante determined long-term contracts, we argue that exchange relationships with alternative governance mechanisms are more likely to terminate prematurely. Specifically, we propose that the reliance on alternative governance mechanisms introduces multiple reference frames for adapting to the same contingency. The reliance on multiple frames of reference creates diverging reference points that are likely to conflict and thus induce ambiguity around adaptive actions.

To illustrate, a supplier facing higher-than-expected labor costs may believe that this circumstance should be managed on an informal basis given the established trust and reciprocal adaptation. The client, on the other hand, may maintain that the contract provides suitable adaptive behavior, especially if the contract entails complex price regulation. In addition to creating uncertainty about the relevant reference point, the diverging frames of references are likely to be conflicting in terms of directing adaptation. The parties' appropriation of value from the exchange will typically characterize the behavior involved in creating contractual reference points (i.e., contract negotiation). Conversely, relational mechanisms rely on reciprocal maximization of the joint value of the transaction. Thus, reference frames based on contracts compared to relational mechanisms are likely to materially conflict in terms of actionable adaptation. Essentially, given alternative governance mechanisms, adaptive behavior risks being non-conform from a contractual perspective, or opportunistic and competitive from a relational perspective (Klein, 1996).

Accordingly, diverse reference frames for adaptive behavior increase the risk of divergent feelings of entitlement and responsibility (e.g., Kaplan, 2008; Pinkley and Northcraft, 1994). As has been established in research on managerial cognition, the presence of alternative, and potentially conflicting, frames invite political bargaining processes aimed at controlling which 
meanings are legitimized (Sewell, 1992; Walch, 1995). Therefore, given the nature of the contingency, exchange parties operating with alternative governance mechanisms may have opposing views on whether formal or relational adaptive mechanisms are preferable. This can result in bargaining and, eventually, ambiguity of adaptive actions (Kaplan, 2008). Thus, while an unambiguously shared reference frame induces effective adaptive behavior, we posit that investments in relational mechanisms in exchange relationships already long-term contractually framed mitigate effective adaptation to unanticipated circumstances. This suggests that premature termination becomes increasingly likely and leads us to our third and final hypothesis:

Hypothesis 3: The simultaneity of longer expected contract duration and investments in relational mechanisms increases the likelihood that an exchange relationship will prematurely terminate.

In sum, we propose a theoretical model in which investments in either longer contract duration or more intense relational mechanisms provide an effective means for contingency adaptation and therefore reduce the probability of premature termination. Yet, their concurrent presence creates ambiguous reference points and restricts the parties' set of adaptive actions, and thus increases the likelihood of premature termination.

\section{METHODS}

\section{Empirical context}

Our empirical setting is the global service-provider industry. Over the last few decades, an increasing number of firms, particularly from the U.S. and Western Europe, have used specialized service providers to reduce operating costs, increase the speed of delivery, access talent, and gain other advantages (Lewin and Peeters, 2006; Manning et al., 2015). Large players, such as U.S.based Accenture, IBM, and HP, India-based Tata Consultancy Group, Infosys, and Wipro, and 
numerous midsize and small providers from both developed and developing countries populate the global service-provider industry. Gartner, Inc. (2008) estimated the total contract value of the global service-provider industry at $\$ 30$ billion. Moreover, the study estimated the average value of the 20 largest outsourcing contracts at $\$ 275$ million with an average contract length of five to six years, but with much variation.

Concerning our focus on premature termination, the global service industry offers ideal testing grounds. Most transactions between clients and service providers are relatively removed from the firms' core strategic areas. Thus, the initiation of an exchange relationship is often driven by factors that are directly comparable within the market. For example, providers of customer support can objectively be compared based on factors such as price. Although some transactions involve relation-specific investments aimed at accommodating specific clients, transacting parties are typically not considered "strategic partners." The industry also encompasses substantial variation in contract duration. In contrast to relationships of a more strategic nature, industry characteristics ensure that firms can (and do) prematurely terminate relationships in response to changing circumstances.

\section{Data collection}

To test our hypotheses, we use data from the service-provider survey run by Offshoring Research Network (ORN), an international research initiative spearheaded by Duke University and involving partner universities in Europe and Asia. Data on service providers is collected both on the firm level (e.g., firm size, client attracting strategies, perceived risks) and on the service level (e.g., locations from which services are provided, margins, service characteristics, and contract renewal rates). 
As of 2012, the service-provider database contained data from 755 providers located in different countries and regions. Listwise deletion of missing data points resulted in a final sample of 170 providers with 378 service-level observations. ${ }^{2}$ The average firm size (measured as the number of employees) in the sample is $1,372(\mathrm{SD}=6112.3)$. The three most important classes of services are software (20.9\%), information technology (19.5\%), and call-center activities (11.1\%). Given our focus on premature termination of fixed-length contracts, we use service-level observations in our regression models. As we were unable to gather information on each transaction, we focus our analysis on the lowest obtainable observation level. Thus, the basic unit of analysis is the class of service (e.g., "call-center") offered by the service provider. Within each class of service, providers typically perform multiple tasks. For example, as part of 'finance and accounting services', providers may perform accounts payable and receivable, cash management, credit card operations, fixed asset accounting, etc.

\section{Measurements}

\section{Dependent variable}

We measured the extent to which service providers had experienced premature relationship termination by asking the respondents: "For each class of services that your company provides and looking solely at the first contract with each client, please indicate the percentage of deals that are terminated before expiration of the first contract." This variable captures the service-specific proportion of transactions that were prematurely terminated. Although we highlight our inability to observe relationship termination at the individual transaction-level, the measure broadly captures the effectiveness of the firm's governance mechanisms. ${ }^{3}$ Given the separation between

\footnotetext{
${ }^{2}$ Although various methods exist to replace missing values (e.g., Royston, 2004), we decided to only use actual responses. We follow the rationale that respondents providing complete information are likely to be more accurate with any particular data they provide than respondents providing incomplete information.

${ }^{3}$ In instances where only a single exchange relationship exists, the variable is measured at the transaction-level
} 
different classes of services, firms' use of contractual and/or relational governance mechanisms is likely to be relative stable. The focus on the service level reduces concerns that unobservable differences between classes of services may confound our analysis. Although respondents were specifically asked to report on the first transaction with each customer, we elaborate on the limitation imposed by our service level measure in the discussion section of the paper.

The initial examination of responses indicated that premature termination does occur within the service-provider industry. On average, $4 \%$ of all the transactions carried out by the respondents were terminated before their completion date $(\mathrm{SD}=0.11)$. Premature termination varies substantially among service types, with $R \& D$ services having the highest average proportion of all transactions prematurely terminated $(11 \%)$ and procurement services the lowest $(1.5 \%)$. While these figures support our analytic focus on service classes, we emphasize the need for a cautious interpretation. As a proportional measure, the data do not directly offer indications of the economic significance of premature relationship termination. Relatively low proportions may indicate that premature terminations are infrequent within the service-provider industry or that service providers have a relatively large number of customers. To investigate the non-trivial frequency of premature termination, we examined the proportion of service providers who had experienced relationship termination prior to contract completion. In total, $36 \%$ of the service providers in our sample had experienced at least one relationship being terminated before the expected contract duration.

\section{Independent variables}

Our first independent variable is contract duration and is measured by the contractually specified relationship duration. Generally, longer contract duration requires that parties actively guard 
against future contingencies and exchange hazards. ${ }^{4}$ In its simplest form, longer contract duration creates more room for variations in factors affecting transaction input and output. Thus, contracts with longer durations will ceteris paribus require more complex governance mechanisms than shorter-term exchange relationships (Williamson, 1985). Operationally, we measured relationship duration as "the average duration of deals currently under contract" for each class of service. By measuring contract duration at the service level, we can make direct comparisons between service classes. Specifically, given firms' relatively stable choice of governance mechanisms, variations in contract duration is likely to be substantially influenced by differences between service class characteristics. Indeed, except for procurement services, the variation in contract duration is significantly larger $(\mathrm{p}<0.05)$ within service class than within firms. Thus, all models included binary variables for service classes.

To further mitigate unobserved variations in contract duration affected by differences in legal dogma (e.g., industry standards) within service classes, two variables were included. The first variable related to the inclusion of specific litigation clauses in the contract. Although contractual safeguards may include a myriad of different technical clauses, the implementation of conflict resolution by arbitration stands out. Essentially, arbitration substitutes formal legal doctrine with a preapproved set of custom rules. Arbitration agreements may introduce substantial discrepancies between the contractual governance and the probability of premature termination. Arbitration increases the competence level of third-party conflict resolution (Williamson, 1985).

\footnotetext{
${ }^{4}$ Typically, the physical length of the contractual agreement has served as an indication of contractual complexity (e.g., Joskow, 1988). However, given the multilingual nature of our sample, a simple word count is likely to be inadequate for determining a relationship's formal governance mechanisms. Moreover, certain aspects of formal contracts may reduce the accuracy of using page length as a proxy for formal governance mechanisms. For example, the content of a letter of intent is likely to increase the physical length of a contract despite the uncertainty regarding its effect as a formal governance mechanism. Conversely, acceptance of legal industry standards does not demand much physical volume, even though industry standards may have wide-ranging formal governance effects. Hence, we focus on the duration of the relationship as a formal mechanism for averting and safeguarding against exchange hazards (Ciccotello et al., 2005; Joskow, 1988).
} 
Increased third party competence, ceteris paribus, reduces contracts influence in terms of reference points for adaptive actions as the cost of thirds party intervention is reduced. Operationally, contractually specified arbitration was coded 1 if respondents indicated that "arbitration location" was one of the client's five most important contract items, and 0 otherwise.

The second variable targeted the selection of a jurisdiction for conflict resolution. While contract duration is less likely to be directly influenced by legal heterogeneity, our inclusion of contractual selection of jurisdiction is motivated by two factors. Contractually establishing specific jurisdictions requires more ex ante investment in contracting. Thus, contract duration may, on average, be longer in order to recoup the added expenses. Moreover, specification of jurisdiction may also indicate a higher level of contractual sophistication (i.e., formal governance). Second, as breach-of-contract remedies differ among jurisdictions, the selection of a specific jurisdiction may indicate anticipation of premature termination. Parties may opt out of the local jurisdiction of the provider's home country in order to secure more favorable breach conditions. This is also known as forum shopping (e.g., Juenger, 1988). The variable was coded one if respondents indicated that "location of litigation governance" was one of the five most important contract items for their clients and 0 otherwise.

To guard against expected relationship duration being driven by transaction factors relating to the goods exchanged, we include a number of additional variables in the models. First, investments in relationship-specific assets require parties to implement specific safeguards and/or extend the duration of the transaction. Longer durations enable the investing party to recoup the initial cost of the investment, possibly in combination with safeguards (e.g., cost-plus provisions, excuse clauses). Thus, controlling for asset specificity simplifies the association between contract duration and the likelihood of premature termination. Three questionnaire items operationalized 
asset specificity at the service level. First, respondents were asked to indicate the extent to which they had invested in client-specific software on a Likert scale ranging from low (1) to high (5). The second item measured investments in infrastructure. The last asset-specificity item related to the service provider's investments in client-specific training. We created an average composite measure to capture the overall level of specific investments made by the service provider (alpha $=$ $0.72)$.

Our second independent variable is investments in relational mechanisms. Respondents were asked to record any specific mechanisms employed to manage and nurture client relationships. To account for differences among service classes, an open-ended question was used: What strategies, if any, has your company developed to nurture and reinforce long-term client relationships? The focus on long-term relationships was motivated by the continuous nature of relationship nurturing mechanisms. Relational mechanisms, unlike formal mechanisms, require that parties maintain the integrity of the social contract throughout the relationship. Moreover, establishing relational mechanisms is subject to time compression diseconomies. Thus, relational mechanisms cannot be established ex ante. ${ }^{5}$ All recorded mechanisms were coded 1 and a summative measure was calculated. Therefore, our measure increased in line with the number of relational mechanisms reported by the respondent. Although the strength of relational mechanisms may compensate for the quantity of mechanisms, our measurement technique only accounts for the scope of relational mechanisms. We are unable to directly measure the depth of investments given the qualitative nature of the mechanisms. Specifically, we refrain from quantitative ordering of different mechanisms. Thus, a firm that had "assigned a senior executive to cultivate relationship with key client individuals" is coded as having invested less than a firm that had

\footnotetext{
${ }^{5}$ We abstract from the transferability of relational mechanisms between exchange relationships, by including a control for prior relationships.
} 
employed both "weekly and monthly business reviews" and "hosted client executive teams for exploratory conversations and facilities tours." Although assigning a senior executive may qualitatively represent a very substantial investment in certain contexts, we highlight our inability to account for qualitative differences between investments. The open-ended nature of the question does not allow relative weights to be placed on certain relational mechanisms. The variable mean suggests that, on average, firms implemented more than two distinct mechanisms $(2.45 ; \mathrm{SD}=$ 2.38), while $73.5 \%$ of all respondents indicated that their firms had at least one mechanism to manage and nurture client relationships. Considerable variation exists among service types, with product-design services being the most relational focused service class $($ mean $=3.5)$.

To distill variance related to investments in relational governance mechanisms, we included two variables related to prior relationships between the client and the service provider. First, prior collaborations may confound our measure of relational mechanisms. For example, previous negative experiences may strengthen the parties' inclination to terminate future contracts rather than adjust to contingencies. Similarly, successful prior collaboration may reduce the probability of termination. Prior collaboration may influence the observed level of relational mechanisms. Positive reputational capital requires fewer direct investments in relationship nurturing owing to the existence of prior reference points. To sidestep the directionality issues and ensure the transferability of reputational capital, the questionnaire item was framed as prior collaboration that was important for the client's choice of the specific service provider. Specifically, respondents were asked to indicate whether prior collaboration was one of the five "most important factors in order for a client to select your company as a service provider." Affirmative answers were coded one, while all other answers were coded zero. 
The second variable was based on prior personal relationships. Private reputational capital may be important in establishing relational reference points. In addition to the reasons mentioned above, controlling for personal relationships enables us to mitigate any bias introduced by turnover in the service provider's management team. Moreover, inclusion of this variable reduces concerns about underestimations of premature termination due to the prevalence of nepotism in some countries. Similar to the measure of prior collaboration, responses indicating that a personal relationship was one of the top five reasons for the relationship were coded as one.

Lastly, we expect the frequency of interactions to positively influence the ease with which relational governance mechanisms can be established. Although the interpretation of this variable is limited by its simplicity, it does indicate whether relational mechanisms are predominately established through active/passive investments.

\section{Additional control variables}

In addition to the controls directly warranted by our main independent variables, we include a number of controls associated with transaction characteristics and premature termination. First, the size of each service area was included. Service provider size may influence the parties' bargaining power in terms of the adaptive actions taken if a contingency arises. Furthermore, the size of the service type may co-vary with premature termination. Large service providers may be less interchangeable and, thus, reduce the likelihood of termination. More indirectly, size may indicate a service provider's willingness to undertake client-specific investments. For example, large and more established service providers may be able to more easily secure the capital needed for investments. Conversely, smaller providers may be more willing to invest in securing longer-term relations with customers. Given the ambiguous influence of service size, a control (measured as the logarithm of the number of employees in each service type) was included in all models. Second, 
we included years of experience with delivering a particular service. Experience may support the development of service-delivery capabilities, which may influence the likelihood of premature terminations. Third, the tenure of the employees actively engaged in providing a service may predict premature termination based on delivery capabilities. However, tenure may also be associated with adaption rigidity, as employees with longer tenures may be less willing to adjust to a contingency and they might insist on sticking to established practices. Moreover, tenure may indicate the existence of positive reputational capital. Tenure was measured using the self-reported average employee tenure in each service class. Although less likely to be manifested than tenure, the general work experience of employees may lead to implicit reliance on established industry norms when adjusting to unanticipated circumstances. More experienced employees may be less affected by the potential negative consequences of premature termination, as they are more likely to be able to find alternative employment. Therefore, more experienced individuals may be less inclined to deviate from their preferred reference points. Fourth, although a specific control for service class size is included, we also control for the overall size of the service provider. In addition to the reasons outlined above, large service providers may be able to reallocate resources between service classes to overcome contingencies, thus reducing the likelihood of termination. Thus, firm size (measured as the logarithm of the number of employees in all service types) was included. Lastly, we include a control for whether the service provider had previously terminated relationships. While this control is limited by its binary nature (affirmative answers were coded 1), client firms with experience in termination may be more knowledgeable about the potential consequences of a contract breach.

\section{RESULTS}


Table 1 presents descriptive statistics and pairwise correlations for all focal variables. An inspection reveals that the average contract duration in the sample is 2.1 years $(\mathrm{SD}=2.2)$, with durations ranging from less than one year for "spot market" contracts to 25 years. This suggests that the service-provider industry exhibits a wide range of contract durations. Cross tabulation of contract duration and service types reveals that duration centers around two years (minimum of 1.25 years in engineering services; maximum of 2.98 years in call-center services). Thus, although premature termination varies substantially between service types, it appears that contract duration remains relatively stable.

Table 1 also illustrates that, on average, relationships within the service industry entail medium levels of relationship-specific investments $($ mean $=2.9 ; \mathrm{SD}=0.9)$. In support of the relevance of specific contractual elements, more than $27 \%$ of the sampled firms indicated that arbitration was among the five most important contract items, while the corresponding figure for litigation location was approximately $23 \%$. However, only $11 \%$ indicated that both contractual terms were critical. Intuitively, this appears to be in line with the view that arbitration reduces the need to specify a litigation location.

$* * *$ Table 1 about here $* * *$

Further inspection of Table 1 reveals several notable correlations. First, as predicted, both relational mechanisms and contract duration are negatively and significantly correlated with premature termination. Moreover, both are positively correlated and significant $(\mathrm{p}<0.05)$ with asset specificity. Relationship-specific investments typically necessitate increased governance safeguards ${ }^{6}$. Thus, relationship-specific investments may be seen as an antecedent of both our main independent variables (i.e. contract duration and relational mechanism). The antecedent, or

\footnotetext{
${ }^{6}$ Safeguards may also be created by co-investments by the other party.
} 
mediating, properties of relationship-specific investments are interesting in their own right and have been the focal point in numerous analyses. However, in terms of our focus on premature relationship termination, relationship-specific investments merely guard against biased estimations. The positive correlations also support our measures of governance mechanisms, as they exhibit the predicted associations with covariates, although we are cautious in this interpretation. Table 1 also illustrates that firm size is negatively $(\mathrm{p}<0.05)$ correlated with premature relationship termination. At face value, this may indicate that larger firms are less likely to terminate ongoing contracts. However, it may can reflect the underlying association between larger service providers and more customers and, thus, lower overall terminations. The highest correlation in Table 1 is found between the overall size of the service provider and the size of the specific service class. Although this correlation is intuitive, we explored the possibility of collinearity. Generally, the pairwise correlations presented in Table 1 do not indicate that multicollinearity is an actionable concern. This conclusion is further supported by the variance inflation factors, which were below critical levels (maximum individual VIF = 3.8 for firm size; average $\mathrm{VIF}=1.7)$.

As our dependent variable measures the proportion of relationships prematurely terminated, we employed a fractional logit regression model to test our hypotheses (Papke and Wooldridge, 1996). Moreover, as the analysis focuses on the service-class level, the analysis includes firm clustering. The first model contains only control variables. Model 2 includes the direct effects of the two governance mechanisms. Finally, Model 3 includes the interaction terms between contract duration and relational mechanisms. All continuous variables were meancentered to reduce nonessential multicollinearity and aid interpretation (Cohen et al., 2003).

*** Table 2 about here $* * *$ 
The negative and significant $(\mathrm{p}<0.05)$ coefficient for contract duration in Model 2 offers support for Hypothesis 1-the longer the contractual duration is, the lower the likelihood that the relationship will be terminated before the expected duration. Hypothesis 2 is supported by the negative and significant $(\mathrm{p}<0.01)$ coefficient for relational mechanisms in Model 2. In Model 3, the positive coefficient $(\mathrm{p}<0.01)$ for the interaction provides initial support for Hypothesis 3 . However, because of the non-linear nature of the fractional logic model, we further probe the interaction effect, correcting for the baseline effect of contract duration (Ai and Norton, 2003; Norton et al., 2004; Buis, 2010). Varying contract duration (long = +1 SD; short = -1 SD) illustrates that investments in relational mechanisms is only associated with a reduced likelihood of premature termination $(\mathrm{p}<0.05)$ when contract duration is short $(-1$ SD). We illustrate this association in Figure 2.

$* * *$ Figure 2 about here $* * *$

Interestingly, Figure 2 suggests a hierarchical ordering of governance mechanisms. Specifically, adjusting for the baseline reduction associated with long contract duration, relational mechanisms do not influence the likelihood of premature termination. Given that the agreement of contract duration precedes establishment of relational mechanisms, adaptive reference points seem locked to the contract even when alternative governance mechanisms are established. Thus, divergent to Hypothesis 3, inclusion of alternative governance mechanism is inconsequential rather than detrimental to adaptation. While establishing and nurturing relational mechanisms may entail substantial costs, especially given longer expected relationship duration, it does not necessarily decrease the risk of premature termination. To illustrate this, Figure 3 plots average marginal effects of relational mechanisms at short/long contract duration.

$* * *$ Figure 3 about here $* * *$ 
The figure clearly illustrates that once contract duration extends above mean length, relational mechanisms cease to influence the likelihood that a relationship will termination prematurely. Thus, the negative association of relational mechanisms on effective contract duration is conditional on the expected duration being short.

We also note that asset specificity is positive and significant $(\beta=0.51, \mathrm{p}<0.05)$. This offers empirical support for the prediction in transaction-cost economics (Shelanski and Klein, 1995) that high asset specificity is deterministic in exchange relationships. Notably, however, specific contractual clauses and the existence of prior relationships - two other important exchange attributes - do not significantly predict the likelihood of premature termination in the sample. Lastly, the regression analysis reveals that service providers who had previously experienced terminated relationships are less likely to experience premature termination. Cautiously interpreted, the association may be indicative of the often substantial costs of premature relationship termination. However, as the association was only marginally significant $(\mathrm{p}<0.06)$ and not the focal point of the analysis, we stress this interpretation as cursory.

In sum, we find empirically support of our hypotheses. However, as we did not find evidence suggesting that a high level of relational governance combined with long contract duration is associated with an increased likelihood of premature termination, the association between the two types of governance mechanisms must be considered as conditional rather than substitutive.

\section{Robustness analysis}

Due to the high correlation between overall firm size and service-class size, we reran the analysis without firm size. The re-specified model did not substantially change the original interpretations. The second re-specified model addressed the latent mediating effect of relationship-specific 
investments. Simple exclusion of the variable measuring relationship-specific investment from the original model produces similar results. Moreover, the original findings proved stable to inclusion of the individual three items used to construct our composite measure. We also investigated whether service providers' reputation in terms of prior prematurely terminated relationship significantly influenced the use of governance mechanisms. Specifically, we regressed previously terminated relationship on contract duration and relational mechanisms independently, including all the controls from the original models. As we did not find significant associations, we tentatively conclude that prior premature termination by service providers does not confound the original estimates.

A key robustness concern relates to endogeneity concerns, especially omitted variable bias. An alternative explanation for our findings may be proffered based on the ongoing condition of the relationship. Specifically, observed difficulties may lead transacting parties to invest in relational governance mechanisms to try to stabilize the relationship. In terms of contract duration, longer duration contracts make it more likely that parties react in terms of adjusting relational governance as relationship condition decline. To address such concerns, we employ a recoding strategy. First, we binary recode our dependent variable ( 0 if no termination occurs, 1 otherwise). By limiting the variance continuity of premature relationship termination, we seek to restrict the biased influence of omitted variables. Essentially, by examining the likelihood of any relationship being prematurely terminated, we restrict the biasing influence of relationship condition. As premature termination of any relationship leads the recoded dependent variable to be set to 1 , we exclude firm clustering. Including all the original control variables, we find a similar negative interaction between contract duration and relational governance mechanisms $(\mathrm{p}<0.10)$ using a logistic regression model. If our results were mainly driven by unobserved factors no interaction 
should be observed, as all marginal differences in relationship condition are restricted. Thus, recoding the dependent variable lends support to our original model. Second, we recode the two independent variables. Again, by restricting variance of relational governance and contract duration, omitted factors should prove less influential. Given the unfeasibility of zero length contract, we recode contract duration based on median length. Thus, the recoded variable takes the value 0 if contract duration was less than 1.5 years, 1 otherwise. In support of the original model, we find a positive interaction effect $(\mathrm{p}<0.05)$.

In sum, the robustness analyses support the estimated direct positive association of contract duration and relational governance mechanisms, and the existence of conditional substitution. Yet, we emphasize that given the nature of our data we are unable to directly address issues of endogeneity. Although the results of the recoding strategy support the original model, this support should be taken as indicative. Based on the establish nature of the ORN service-provider database, we were unable to find suitable instrumental variables. The limitation section of this paper expands on possible effects of our empirical limitation.

\section{DISCUSSION AND CONCLUSION}

We study how investments in relational mechanism in relationships already governed by contracts affect premature termination of exchanges. Based on the risk of diverging reference frames, we propose that the simultaneous existence of alternative governance mechanisms is detrimental for effective contingency adaptation. If either a long-term contract or relational mechanisms effectively govern a relationship, ex-post contingencies are likely to lead to adaptation rather than termination of the exchange. Yet, if a relationship effectively governed by a long-term contract is subsequently augmented by relational mechanisms, ex-post contingencies are likely to result in 
ambiguity regarding the preferred adaptive reference point, thereby increasing the likelihood of termination.

We find support for the direct association of governance mechanisms in a large sample of exchange relationships from the international service-provider context. However, the analyses also indicate that the association between contract duration and relational governance mechanisms is more complex than previously documented. Specifically, we find that the two types of governance mechanisms should be viewed as discrete choice variables. In effect, a relationship governed by a short duration contract may be complimented by relational mechanisms to strengthen reference frames, and thus reduce the likelihood of premature termination. However, the broad scope of reference frame provided by long duration contracts stifles adaptive reference points created through relational mechanisms. Thus, the effect of relying on relational mechanisms is conditional on the extent of existing formal structures. The interpretation of this result relates to the temporal and behavioral aspects of governance structures, wherein formal governance structures such as contract duration precede investments in relational mechanisms. ${ }^{7}$ Given the subsequent nature of informal governance mechanisms, the results raise question about their general effectiveness in mitigating premature termination.

A key contribution of this research relates to our understanding of premature contract termination. Despite having received limited attention (Schepker et al., 2014), premature termination can have severe consequences for firm dynamics. For example, as firms invest in relation-specific assets that instill bilateral dependencies between the transacting parties, they become particularly vulnerable to premature termination (Williamson, 2002). Parties cannot easily

\footnotetext{
${ }^{7}$ However, continuation of relationships after the predetermined termination date may change the sequential order in which governance mechanisms are effective. Alternative ordering may, for example, mean that informal governance mechanisms act as the foundation of formal contracting.
} 
find replacements for goods supplied by virtue of specific investments. Therefore, we emphasize the criticality of premature termination in terms of examining differences between governance mechanisms.

More specifically, by focusing on parties' abilities to adapt to contingencies and the effects of adaptation on premature termination, we contribute to the discussion of how different governance mechanisms affect overall value creation in exchange relationships. Specifically, while research has tended to view informal relational governance and formal contracts as substitutes (Gulati and Nickerson, 2008), recent research argues that formal and relational governance mechanisms may be complementary (e.g., Poppo and Zenger, 2002; Puranam and Vannestre, 2009). Informal aspects such as trust may fil the gaps left by formal mechanisms (cf. Arrow, 1974) and the non-opportunistic intentions of trustworthy parties effectively curb opportunism, which allow for flexible adaptation and lower set-up costs (Carson et al., 2006). We contribute to this debate by suggesting that effective governance structures may function as reference points for adaptive behavior in unanticipated circumstances (Hart and Moore, 2006), which raises the question of if and when relational governance mechanisms may effectively be employed in fixed-duration exchange relationships. As exchange relationships require a formal contract to provide parties with rights and obligations (Shavell, 2004), it is tempting to assume that ex-ante investments in sophisticated formal governance structures are more efficient in absolute terms than investments in ex-post relational mechanisms. First, given the ex-ante implementation of formal mechanisms, under-specification may not become apparent until a contingency arise. Second, subsequent investments in relational mechanisms do not necessarily ensure adaption given the existing formal reference point. Although parties may realize, ex-post, that the relationship is contractually underspecified and establish informal governance mechanisms to try to remedy this, 
they may still prefer formal reference frames given the predefined duration of the relationship. In other words, substituting a formal adaptive reference point with one build on relational mechanisms effectively requires a willingness to disregard specific elements, or the entirety, of the contract.

Therefore, we suggest that the current perception of formal and informal governance structures as supplementary or complimentary is overly simplistic, especially with respect to fixedlength exchange relationships (see discussions by Brown et al., 2000; Dyer and Chu, 2003; Li et al., 2010; Poppo and Zenger, 2002). Temporal differences in establishing formal and informal reference points are crucial when examining how different governance mechanisms relate to each other. While relational governance mechanisms may be ineffective at the onset of an exchange relationship due to the ongoing nature of trust building, contracts create a point of reference for adaptation upon the initiation of relationship. However, this temporal aspect has seldom been explicated as a determinant of contingency adaptation. As already mentioned, informal governance requires that parties engage in non-competitive trust building in an ongoing, reciprocal manner. Thus, relational mechanisms cannot be created immediately at the onset of an exchange relationship, but must be nurtured over time. Indeed, the ongoing nature of establishing informal governance mechanisms is clearly identified by the frequent use of transaction history as a proxy for trust (Carson et al., 2006).

Importantly, relational mechanisms always rest on a contractual foundation established at the initiation of the exchange relationship. Some authors argue that informal governance may be a less costly alternative to vertical integration or formal contracting (Hill, 1990; Uzzi, 1997). However, contractual specifications are still a prerequisite for the initial creation of an exchange relationship. Therefore, at the absolute minimum level of formal contracting, parties to a 
transaction must be identified, the property rights of the exchanged good must be determined and payment terms must be settled (Williamson, 1991; Hart and Moore, 1990).

Obviously, we acknowledge that contractual mechanisms may also invoke elements of relational mechanisms. In our conception of contract duration, longer expected duration may afford time for relational mechanism to evolve. Moreover, the establishment of a long-term contract can also be to a large extent be explained by the presence of 'institution-based trust', wherein the duration of the contract is determined by a degree of trust in third-party structures independent of the dyadic relationship (McKnight et al., 1998; Pavlou and Geffen, 2004; Shapiro, 1987). Yet, for the reasons outlined above, we hold that the relationship between formal and relational governance mechanisms should be viewed as conditional rather than as complementary/substitutive, especially in matters of understanding adaptive behavior and premature termination.

Notwithstanding the implications of our study, we encourage future research to address some notable limitations, mainly concerned with our empirical design. First, although we rely on a well-established survey instrument to construct our set of variables, their subjective nature warrants mentioning. Specifically, the sole reliance on self-reported measures may bias our findings. For example, respondents may not be fully knowledgeable about their level of relationship-specific investments. Moreover, respondents may vary in terms of assessing how much a specific investment relates to the focal party. Although in practice, this bias relates to our control variables, we highlight the need for future research that considers more objective measures.

A second and potentially more problematic limitation relates to our focus on contingency adaptation and ambiguous reference frames. Even though we have strong theoretical reasons for explicitly focusing on this aspect of governance mechanisms, our analysis does not directly 
measure whether contingencies actually arise. Therefore, we urge cautious interpretation of our results given our inability to empirically establish the exact reasons for premature termination. We propose that parties' inabilities to adapt are theoretically linked to premature termination of an exchange relationship. However, other factors may result in premature termination. For example, highly effective parties may be able to complete transactions faster than the predetermined termination date. Although this is technically a contingency, such situations are absent from the theoretical arguments made in this paper.

Relatedly, the nature of our data limits our ability to econometrically establish causation and thus rule out the endogeneity problem (Hamilton and Nickerson, 2003; Shaver, 1998). Specifically, given the temporal ordering of relationship termination and the choice of governance mechanisms, we were unable to identify any reasonable alternatives for expecting premature termination to affect firms' choice of contract duration and/or relational mechanisms (see e.g., Hahn et al., 2011; Stock et al., 2012). However, several confounding factors may impact the interaction between the two governance mechanisms and thus bias the coefficient estimates. For example, longer contract duration may facilitate increased reliance on relational mechanisms which raises questions about the exogenous nature of the governance mechanisms (however, if longer duration contracts do afford greater investments in relational mechanisms, the results pointing to the conditional substitution between the two governance mechanisms highlight the criticality of accounting for the temporal order of establishing governance mechanisms). Also, while we control for prior relationships between exchange parties, we are unable to completely mitigate potential influences stemming from prior transactions. Therefore, although our robustness tests including the estimated negative interaction effect between the two governance mechanisms suggest that our results are conservatively estimated, we acknowledge that we cannot provide 
absolute proof of the absence of the endogeneity problem. Our results should thus be interpreted as an approximation of our theoretical ideas, rather than as objective evidence of the underlying mechanisms.

Last, as our main variables are aggregated to the service class level of analysis, we are unable to empirically isolate individual transaction chrematistics. While we theoretically purport a negative relationship between contract duration and relational governance mechanisms, the empirical support is at a higher aggregated level of analysis. Thus, we highlight that our results in support our main hypotheses - that the effect of establishing relational governance mechanisms on premature termination is conditional on the preceding formal contracting - is based on average service class measures.

In conclusion, we emphasize the importance for future research to continue premature contract termination. While we have paid attention to the adaptive actions associated with the relationship between contract duration and investments in relational mechanisms through, we strongly encourage future research to further untangle why contracts terminate before time, how firms can manage such processes, and what the consequences are.

\section{REFERENCES}

Ai C, Norton EC. 2003. Interaction terms in logit and probit models. Economic Letters 80: 123129.

Amitt R, Zott C. 2001. Value Creation in E-Business. Strategic Management Journal 22: 493-520. Argyres N, Mayer KJ. 2007. Contract design as a firm capability: An integration of learning and transaction cost perspectives. Academy of Management Review 32(4): 1060-1077.

Arrow KJ. 1974. The Limits of Organization. New York: W.W. Norton.

Arruñada B, Garicano L, Vázquez L. 2001. Contractual allocation of decision rights and incentives: The case of automobile distribution. Journal of Law, Economics, and Organization 17: 257-284.

Barthélemy J, Quélin BV. 2006. Complexity of outsourcing contracts and ex post transactions costs: An empirical investigation. Journal of Management Studies 43(8): 1775-1797. 
Brown JR, Dev CS, Lee DJ. 2000. Managing marketing channel opportunism: The efficacy of alternative governance mechanisms. Journal of Marketing 64: 51-65.

Buis, M. 2010. "Stata tip 87: Interpretation of interactions in non-linear models." The Stata Journal 10: 305-308

Carson SJ, Madhok A, Wu T. 2006. Uncertainty, opportunism, and governance: The effects of volatility and ambiguity on formal and relational contracting. Academy of Management Journal 49: 1058-1077.

Claro DP, Hagelaar G, Omta O. 2003. The determinants of relational governance and performance: how to manage business relationships? Industrial Marketing Management 32(8): 703-716.

Ciccotello CS, Hornyak MJ, Piwowar MS. 2004. Research and development alliances: Evidence from a federal contracts repository. Journal of Law and Economics 47: 123-589.

Coase RH. 1937. The nature of the firm. Economica 4(16): 386-405.

Coase RH. 2006. The conduct of economics: the example of Fisher Body and General Motors. Journal of economics and management strategy 15(2): 255.

Cohen, J., Cohen, P., West, S. G. and Aiken, L. S. (2003). "Applied multiple regression/correlation analysis for the behavioral sciences”. Erlbaum: Hillsdale, NJ.

Cornelissen JP, Werner MD. 2014. Putting Framing in Perspective: A Review of Framing and Frame Analysis across the Management and Organizational Literature. The Academy of Management Annals 8(1): 181-235.

Dyer JH, Chu W. 2003. The role of trustworthiness in reducing transaction costs and improving performance: Empirical evidence from the United States, Japan, and Korea. Organization Science 14: 57-68.

Dyer JH, Singh H. 1998. The relational view: Cooperative strategy and sources of interorganizational competitive advantage. Academy of Management Review 23(4): 660-679.

Ethiraj SK, Kale P, Krishnan MS, Singh JV. 2005. Where do capabilities come from and how do they matter? A study in the software services industry. Strategic Management Journal 26(1): 2545.

Fehr E, Hart O, Zehnder C. 2014. How Do Informal Agreements and Revision Shape

Contractual Reference Points? Journal of the European Economic Association: forthcoming.

Ganglmair B. 2009. Early Contract Termination and Specific Investment. Unpublished manuscript, University of Zurich.

Gartner. 2008. Gartner on outsourcing, 2008-2009. Gartner: ID Number: G00164206.

Ghoshal S, Moran P. 1996. Bad for practice: A critique of the transaction cost theory. Academy of Management Review 21: 13-47.

Goldberg VP. 1976. Regulation and Administered Contracts. Bell Journal of Economics 7(2): 426448.

Granovetter M. 1985. Economic action and social structure: The problem of embeddedness. American Journal of Sociology 91: 481-510.

Gulati R, Nickerson JA. 2008. Interorganizational Trust, Governance Choice, and Exchange Performance. Organization Science 19(5): 688-708.

Hahn J, Ham JC, Moon HR. 2011. The Hausman test and weak instruments. Journal of Econometrics 160: 289-299. 
Hamilton BH, Nickerson JA. 2003. Correcting for endogeneity in strategic management research. Strategic Organization, 1(1): 51-78.

Hart O, Moore J. 1990. Property rights and the nature of the firm. Journal of Political Economy, 98(6): 1119-1158.

Hart O, Moore J. 2006. Contracts as reference points. The Quarterly Journal of Economics. 123(1): $1-48$.

Hart O. 2008. Economica Coase Lecture: Reference points and the theory of the firm.

Economica 75(299): 404-411.

Heide J, John G. 1992. Do norms matter in marketing relationships? Journal of Marketing 56: 32 44.

Hill C. 1990. Cooperation, opportunism, and the invisible hand: implications for transaction cost theory. Academy of Management Review 15: 500-513.

Inkpen AC, Tsang EWK. 2005. Social capital, networks, and knowledge transfer. Academy of Management Review 30(1): 146-165.

Joskow PL. 1987. Contract duration and relationship-specific investment: empirical evidence from coal markets. The American Economic Review 77(1): 168-185.

Joskow PL. 1988. Asset specificity and the structure of vertical relationships: empirical evidence. Journal of Law, Economics, and Organization 4: 95-117.

Juenger, FK. 1988. Forum shopping, domestic and international. Tulin Law Review 63, 553.

Kale P, Dyer JH, Singh H. 2002. Alliance capability, stock market response, and long-term alliance success: The role of the alliance function. Strategic Management Journal 23: 747-767.

Kaplan S. 2008. Framing contests: Strategy making under uncertainty. Organization Science 19(2): 729-752.

Klein B. 1996. Why hold-ups occur: the self-enforcing range of contractual relationships. Economic inquiry 34(3): 444-463.

Klein B, Crawford RG, Alchian AA. 1978. Vertical integration, appropriable rents, and the competitive contracting process. Journal of Law and Economics 21(2): 297-326.

Knoeber CR. 1989. A Real Game of Chicken: Contracts, Tournaments, and the Production of Broilers. Journal of Law, Economics, and Organization 5(2): 271-292.

Lane PJ, Koka BR, Pathak S. 2006. The reification of absorptive capacity: A critical review and rejuvenation of the construct. Academy of Management Review 31(4): 833-863.

Larsen MM, Pedersen T, Slepniov D. 2010. LEGO Group: An outsourcing journey. Case 9B10M094, Ivey Management Services.

Larsen MM, Manning S, Pedersen T. 2013. Uncovering the hidden costs of offshoring: The interplay of complexity, organizational design, and experience. Strategic Management Journal 34(5): 533-553.

Lewin AY. Peeters C. 2006. Offshoring work: Business hype or the onset of fundamental transformation? Long Range Planning 39(3): 221-239.

Li JJ, Poppo L, Zhou KZ. 2010. Relational mechanisms, formal contracts, and local knowledge acquisition by international subsidiaries. Strategic Management Journal 31: 349-370.

Macneil IR. 1978. Contracts: adjustment of long-term economic relations under classical, neoclassical and relational contract law. Northwestern University Law Review 72: 854-905. 
Macneil IR. 1980. The new social contract: An inquiry into modern contractual relations. New Haven, CT: Yale University Press.

Manning S, Larsen MM, Bharathi P. 2015. Global Delivery Models: The role of talent, speed, and time-zones in the global outsourcing industry. Journal of International Business Studies forthcoming.

March JC, Simon HA. 1958. Organizations. New York: Wiley.

McKnight D.H., Cummings L.L., Chervany N.L., 1998. Initial Trust Formation in New Organizaitonal Relationships. Academy of Management Review, Vol 23, N. 3, pp. 473-490.

Norton, E., H. Wang and C. Ai. (2004). "Computing interaction effects and standard errors in logit and probit models". The Stata Journal 4: 154-167.

Ostrom E, Walker J, Gardner R. 1992. Covenants with and without a sword: Self-governance is possible. American Political Science Review 86(2): 404-417.

Papke, L.E., Wooldridge, J.M., 1996. Econometric methods for fractional response variables with an application to 401(k) plan participation rates. Journal of Applied Econometrics 11: 619632.

Parmigiani A, Rivera-Santos M. 2011. Clearing a path through the forest: A meta-review of interorganizational relationships. Journal of Management 37: 1108-1136.

Pinkley RL, Northcraft GB. 1994. Conflict frames of reference: Implication for dispute processes and outcome. Academy of Management Journal 37: 193-205

Poppo L, Zenger T. 2002. Do formal contracts and relational governance function as substitutes or complements? Strategic Management Journal, 23(8): 707-725.

Poppo L, Zhou, KZ, Zenger T. 2008. Examining the conditional limits of relational governance: Specialized assets, performance ambiguity, and long-standing ties. Journal of Management Studies 45: 1195-1216.

Puranam P, Vanneste B. 2009. Trust and governance: Untangling a tangled web. Academy of Management Review 34(1): 11-31.

Ring PS, Van de Ven A. 1992. Structuring cooperative relationships between organizations. Strategic Management Journal 13(7): 483-498.

Royston P. 2004. Multiple imputation of missing values. Stata Journal 4(3): 227-241.

Schepker DJ, Oh WY, Marynov A, Poppo L. 2014. The many features of contracts: Moving beyond structure and safeguarding to coordination and adaptation. Journal of Management 40(1): 193-225.

Sewell WF. 1992. A theory of structure: Duality, agency, and transformation. American Journal of Sociology 98(1): 1-29.

Shapiro S.P., 1987. "The Social Control of Impersonal Trust" Americal Journal of Sociology, 3 : 623-658.

Shavell, S. 2004. Foundations of economic analysis of law. Harvard University Press.

Shaver JM. 1998. Accounting for endogeneity when assessing strategy performance: does entry mode choice affect FDI survival?. Management Science, 44(4); 571-585.

Shelanski HA, Klein P G. 1995. Empirical research in transaction cost economics: A review and assessment. Journal of Law, Economics, and Organization 11(2): 335. 
Snow DA, Burke Rochford E Jr, Worden SK, Benford RD. 1986. Frame alignment processes, micromobilization and movement participation. American Sociological Review 54: 464-481.

Stock JH, Wright JH, Yogo M. 2012. A survey of weak instruments and weak identification in generalized method of moments. Journal of Business \& Economic Statistics. 20(4): 518-529.

Uzzi B. 1997. Social structure and competition in interfirm networks: the paradox of embeddedness. Administrative Science Quarterly 42: 35-67.

Walsh JP. 1995. Managerial and organizational cognition: Notes from a trip down memory lane. Organization Science 6(3): 280-321.

Weber L, Mayer KJ, Macher JT. 2011. An analysis of extendibility and early termination provisions: The importance of framing duration safeguards. Academy of Management Journal, 54: 182-202.

Williamson OE. 1975. Markets and hierarchies: analysis and antitrust implications : a study in the economics of internal organization. New York, NY: Free Press.

Williamson OE. 1985. The Economic Institutions of Capitalism. Free Press: New York.

Williamson OE. 1991. Comparative economic organization: The analysis of discrete structural alternatives. Administrative Science Quarterly 36(2): 269-296.

Williamson, O. E. 1996. The mechanisms of governance. New York: Oxford University Press.

Williamson OE. 2002. The Theory of the Firm as Governance Structure: From Choice to Contract. Journal of Economic Perspectives 16(3): 171-195.

Zaheer A. McEvily B, Perrone V. 1998. Does trust matter? Exploring the effects of interorganizational and interpersonal trust on performance. Organization Science 9(2): 141-159.

Zaheer A, Venkatraman N. 1995. Relational governance as an interorganizational strategy: An empirical test of the role of trust in economic exchange. Strategic Management Journal 16: 373392. 


\section{FIGURE 1: FORMAL AND INFORMAL GOVERNANCE}

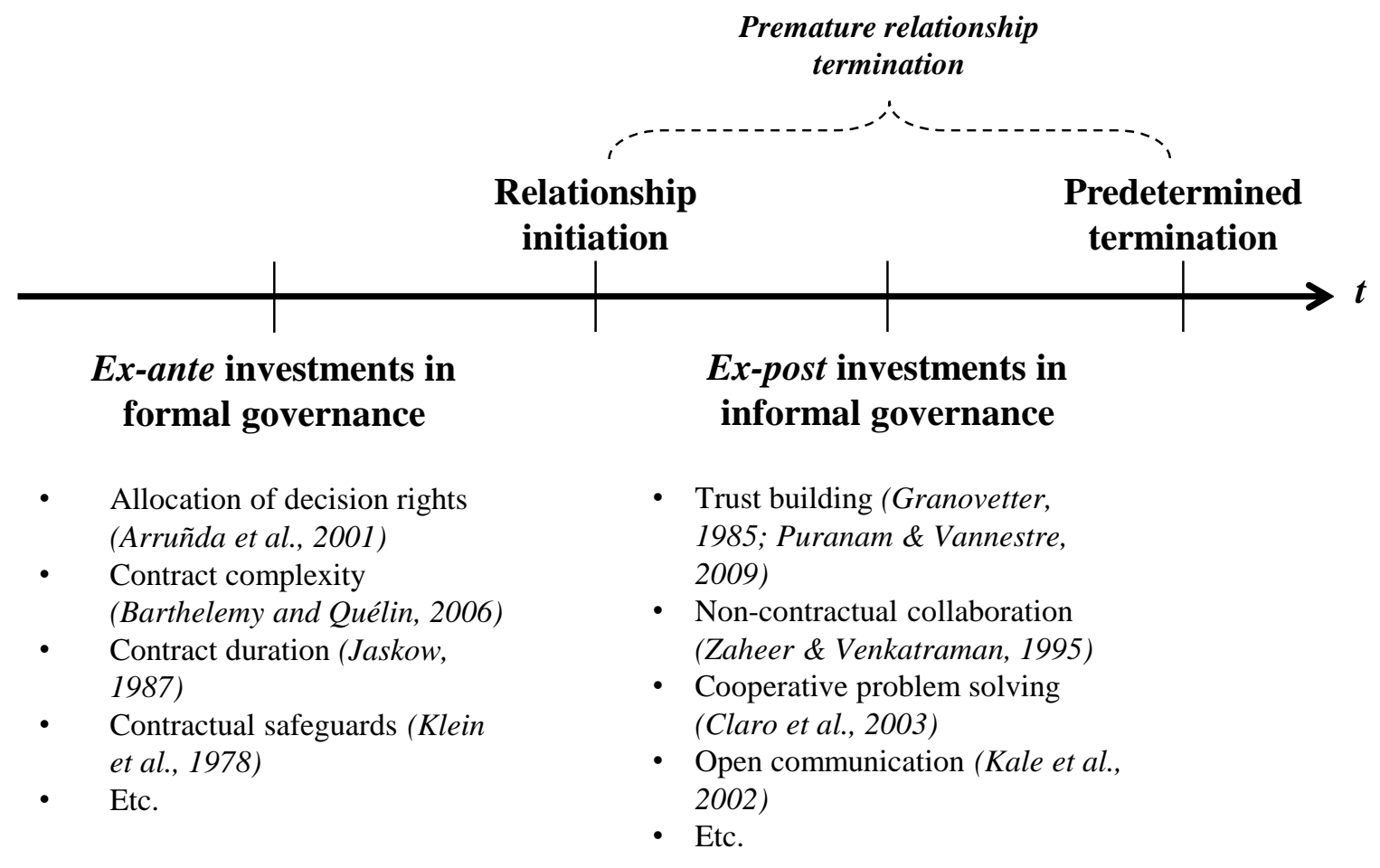


FIGURE 2: TWO-WAY INTERACTION WITH PREMATURE TERMINATION AS DEPENDENT VARIABLE

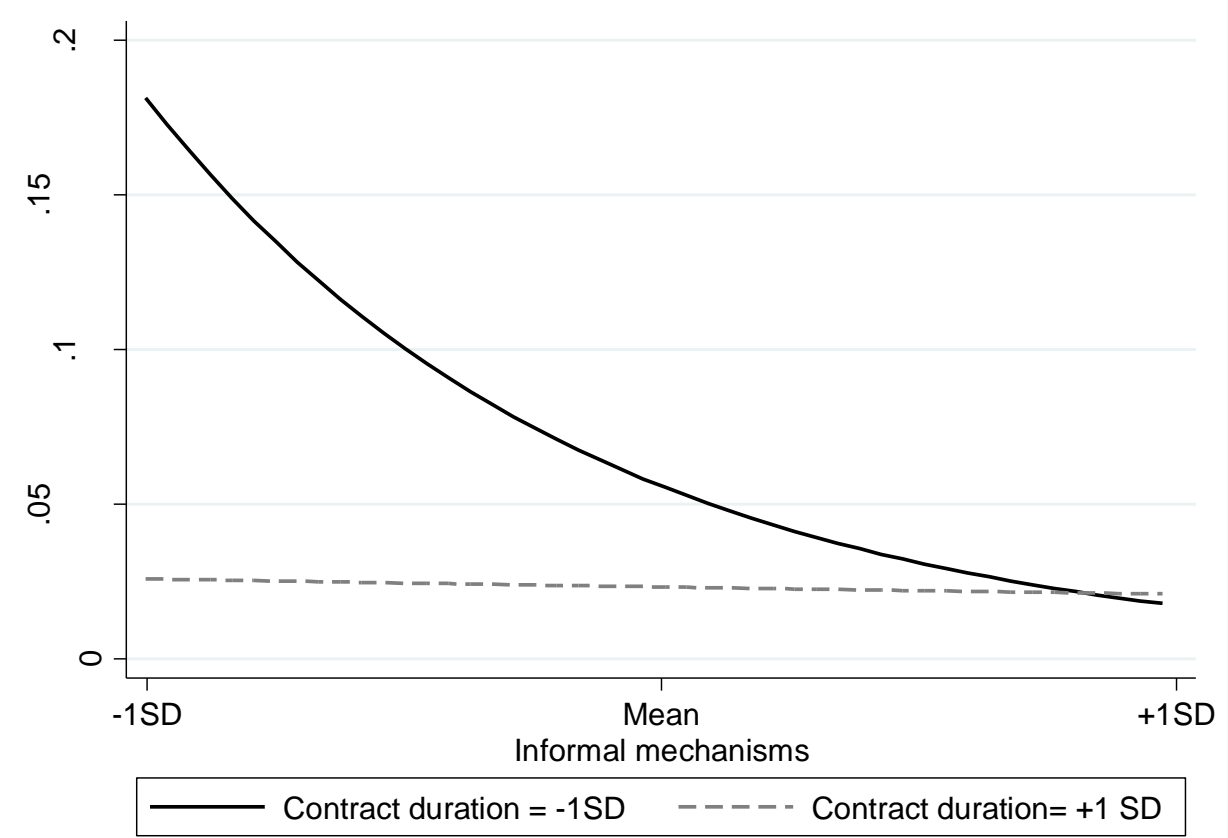

FIGURE 3: AME OF INFORMAL MECHANISMS WITH PREMATURE TERMINATION AS DEPENDENT VARIABLE

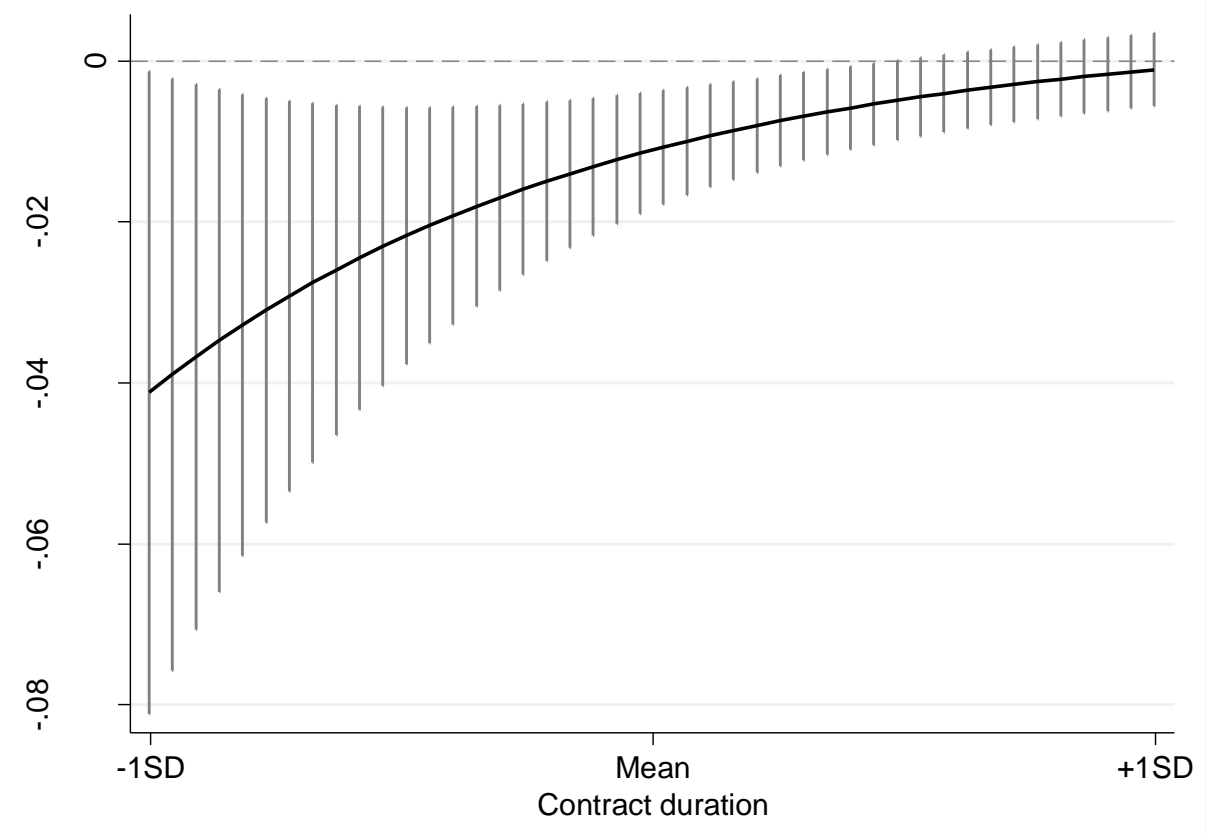




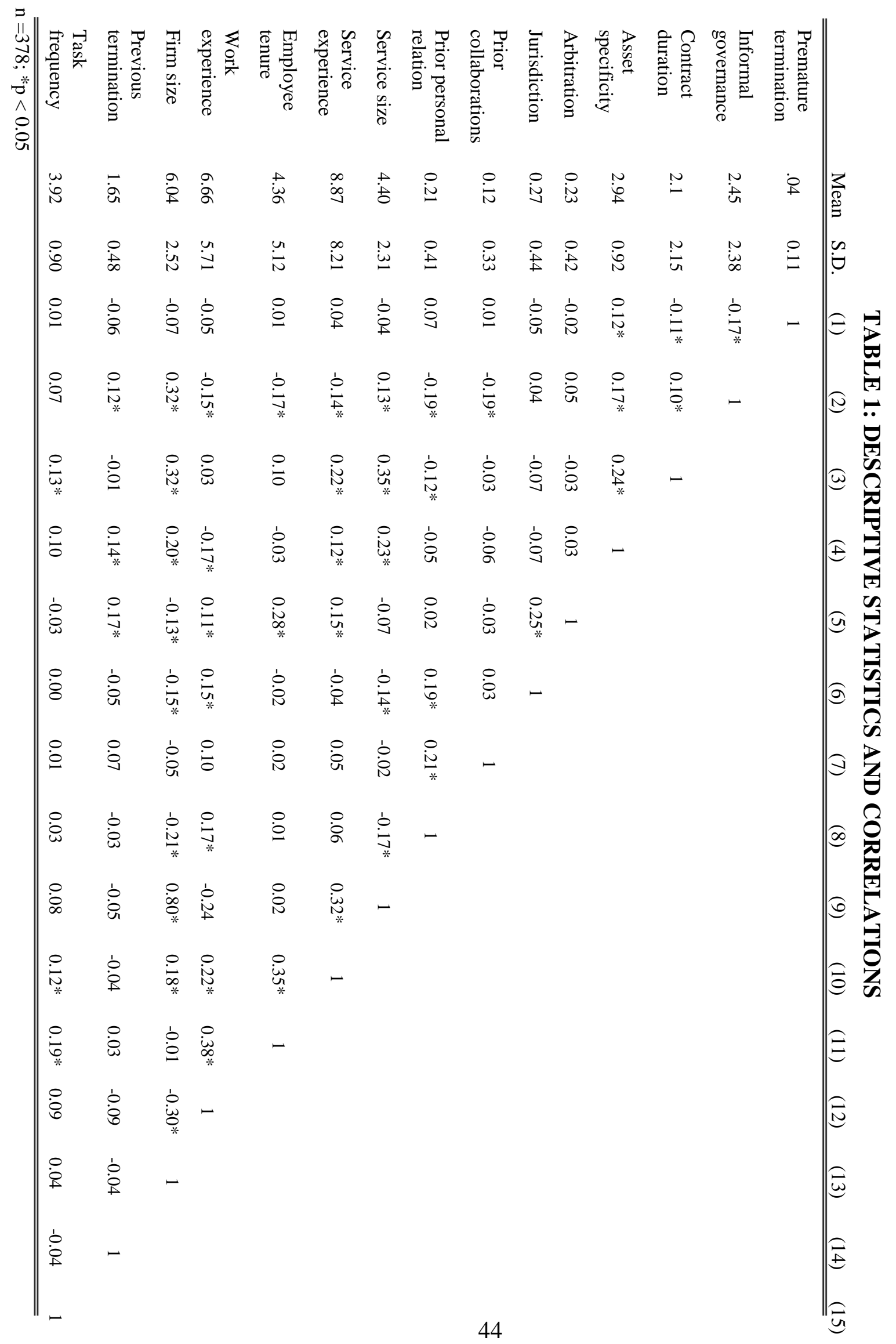


TABLE 2: FRACTIONAL LOGIT REGRESSION ANALYSIS FOR PREMATURE TERMINATION

\begin{tabular}{|c|c|c|c|}
\hline Variable & Model 1 & Model 2 & Model 3 \\
\hline Asset specificity & $\begin{array}{l}0.38 \\
(0.22)\end{array}$ & $\begin{array}{l}0.51^{*} \\
(0.21)\end{array}$ & $\begin{array}{l}0.51^{*} \\
(0.20)\end{array}$ \\
\hline Jurisdiction & $\begin{array}{l}-0.32 \\
(0.54)\end{array}$ & $\begin{array}{l}-0.09 \\
(0.56)\end{array}$ & $\begin{array}{l}0.05 \\
(0.59)\end{array}$ \\
\hline Arbitration & $\begin{array}{l}-0.22 \\
(0.57)\end{array}$ & $\begin{array}{l}-0.15 \\
(0.60)\end{array}$ & $\begin{array}{l}-0.23 \\
(0.62)\end{array}$ \\
\hline Prior collaboration & $\begin{array}{l}-0.26 \\
(0.52)\end{array}$ & $\begin{array}{l}-0.44 \\
(0.43)\end{array}$ & $\begin{array}{l}-0.40 \\
(0.43)\end{array}$ \\
\hline Prior personal relation & $\begin{array}{l}0.53 \\
(0.47)\end{array}$ & $\begin{array}{l}0.24 \\
(0.37)\end{array}$ & $\begin{array}{l}0.12 \\
(0.38)\end{array}$ \\
\hline Service size & $\begin{array}{l}0.05 \\
(0.09)\end{array}$ & $\begin{array}{l}0.01 \\
(0.09)\end{array}$ & $\begin{array}{l}-0.01 \\
(0.09)\end{array}$ \\
\hline Service experience & $\begin{array}{l}0.01 \\
(0.01)\end{array}$ & $\begin{array}{l}0.01 \\
(0.01)\end{array}$ & $\begin{array}{l}0.02 \\
(0.01)\end{array}$ \\
\hline Employee tenure & $\begin{array}{l}0.02 \\
(0.03)\end{array}$ & $\begin{array}{l}-0.01 \\
(0.02)\end{array}$ & $\begin{array}{l}-0.02 \\
(0.03)\end{array}$ \\
\hline Work experience & $\begin{array}{l}-0.07 \\
(0.04)\end{array}$ & $\begin{array}{l}-0.05 \\
(0.04)\end{array}$ & $\begin{array}{l}-0.05 \\
(0.04)\end{array}$ \\
\hline Firm size & $\begin{array}{l}-0.18^{*} \\
(0.08)\end{array}$ & $\begin{array}{l}-0.02 \\
(0.08)\end{array}$ & $\begin{array}{l}-0.01 \\
(0.08)\end{array}$ \\
\hline Prior termination & $\begin{array}{l}-0.61 \\
(0.07)\end{array}$ & $\begin{array}{l}-0.62 \\
(0.33)\end{array}$ & $\begin{array}{l}-0.67 * \\
(0.33)\end{array}$ \\
\hline Task frequency & $\begin{array}{l}-0.01 \\
(0.15)\end{array}$ & $\begin{array}{l}0.11 \\
(0.14)\end{array}$ & $\begin{array}{l}0.14 \\
(0.14)\end{array}$ \\
\hline Informal governance & & $\begin{array}{l}-0.30 * * \\
(0.10)\end{array}$ & $\begin{array}{l}-0.27 * * * \\
(0.08)\end{array}$ \\
\hline Contract duration & & $\begin{array}{l}-0.26^{*} \\
(0.10)\end{array}$ & $\begin{array}{l}-0.20 * \\
(0.08)\end{array}$ \\
\hline $\begin{array}{l}\text { Contract duration } \mathrm{x} \text { informal } \\
\text { governance }\end{array}$ & & & $\begin{array}{l}0.10 * * \\
(0.04)\end{array}$ \\
\hline Log pseudo likelihood & -51.62 & -49.18 & -48.76 \\
\hline
\end{tabular}

